\title{
Los Municipios y las Provincias en la Argentina en $196 \mathrm{I}^{(*)}$
}

\section{A) ORGANISMOS}

i) El Consejo Federal de inversiones

El Consejo Federal de Inversiones es un organismo permanente de investigación, coordinación y asesoramiento, encargado de recomendar las medidas necesarias para una adecuada política de inversiones y una mejor utilización de los distintos medios económicos conducentes al logro de un desarrollo basado en descentralización.

No obstante sus poderes de asesoramiento, condiciona algunos aspectos del proceso económico provincial.

Nació de los tratados interprovinciales y ha promovido estudios importantes para las Provincias y los Municipios argentinos que irán adquiriendo la difusión que merecen.

2) El Instituto de desarollo del Valle Inferior del Río Negro.

Inspirado en los métodos de eficacia, se creó en agosto del pasado año este Instituto, cuya novedad está en que esta persona de Derecho público con autarquía y personalidad jurídica de Derecho privado, toma a su cargo todo un sistema regional a promover mediante la mayor suma de facultades que puedan atribuirse por legislación delegada o investidura administrativa.

Sus órganos de administración son el Consejo administrativo y el Gerente general. En el Consejo de administración participan tres representantes de los usuarios de los servicios de agua, energía y miembros de cooperativas.

El patrimonio de este Instituto está formado por las tierras del dominio privado de la Provincia en el Valle Inferior, por las aporta-

(*) La fuente de esta información ha sido un artículo publicado por Pedro J. Frlas (h), en "Jurisprudencia Argentina", el 6 de febrero del año en curso. 
ciones del Gobierno, de la Nación u organismos nacionales, por «los ingresos y utilidades que arroje el ejercicio de sus actividadesm, etc. gional.

Constituye este Instituto un ejemplo singular de planeamiento re-

B) ORGANIZACION Y FLNCIONAMIENTO

I) Carta orgánica de Santiago del Estero

En las Provincias argentinas hay un intenso movimiento de actualización de leyes municipales, del que constituye una realidad precursora la Carta que el 25 de julio de 1961 entró en vigor sancionada por la Convención constituyente municipal de la ciudad de Santiago del Estero.

La Carta consta de I3C artículos, agrupados en nueve títulos, que abarcan la materia municipal, y aunque la estructura del gobierno municipal no cambia en dos departamentos, se aprecia una notable diferencia, en lo referente a la actualización y ordenamiento de sus órganos y atribuciones, entre las leyes orgánicas vigentes y esta Carta, que viene a constituir, dentro del panorama municipal argentino, un acontecimiento notable.

\section{2) La Carta orgánica municipal de La Banda}

La ciudad de La Banda, como Municipio de primera categoría, eligrió su Convención municipal, en virtud de la nueva disposición constitucional santiagueña. Dicha Convención está integrada por 24 miembros, 16 convencionales de la Unión Civica Radical del Pueblo, como mayoría, 5 de la Unión Civica Radical Intransigente y 3 Autonomistas.

El plazo para la sanción de la Carta vencía el día 28 de junio del año pasado, pero su trámite fue accidentado por disilencias internas surgidas entre los convencionales de la mayoría. La Convención logró mantener su quorum legal, conservando los miembros de las minorias y sólo cinco de la mayoría.

Los miembros ausentes fueron expulsados y reemplazados por los suplentes que se reincorporaron.

Los expulsados no interpusieron recursos y la Convención sancionó la primera Carta orgánica municipal, que precedida de un preámbulo consta de I2I artículos y las disposiciones transitorias. 
C) REFORMAS CONSTITUCIONALES:

1) Reformas constitucionales en Santa Fe

La vigente Constitución data de 1900 y aunque en I921 y 1949 tuvo modificaciones sustanciales, éstas quedaron sin efecto por lus circunstancias políticas. Ahora se proyecta la reforma de la Constitución, para acomodarla a los tiempos que vivimos. La Ley que sanciona el proyecto de reforma de la Constitución la declara necesaria salvo en su articulo 4, que hace de la cirudad de Santa Fe Capital de la Provincia.

El sistema electoral es de voto restringido (sistema D'Hont), con representación proporcional de las minorías.

Las fechas de instalación y mandato son el is de enero y el 15 de abril del año actual. El mandato no podrá prorrogarse.

Esta Ley formalmente correcta, inicia un proceso de revisiones constitucionales inspiradas en el propósito de certeza jurídica y de renovación de estructuras.

2) Reforma constitucional en San Luis

Con menos amplitud que en la de Santa Fe, la legislatura de San Tuis ha declarado ia necesidad de esta reforma.

Se prevé que la elección de miembros de la Convención se llevará a cabo conjuntamente con la de Gobernador y renovación de la legislatura. La Convención se desarrollará en la ciudad de Sian Luis, entre el 31 de enero y el 30 de abril del corriente año de 1962 , sin que pueda prorrogarse su mandato.

Bajo algunos aspectos se ha objetado la legalidad de esta declaración.

\section{3) Reforma constitucional en Tucumán}

Una Ley sancionada el 27 de noviembre próximo pasado, declaró necesaria la revisión casi total de la Constitución.

La elección de convencionales se efectuará conforme a las disposiciones electorales provinciales, según el patrón nacional. El cargo es incompatible con los de los poderes ejecutivo y judicial. No se fija la fecha de instalación, pero se da un plazo de ciento cincuenta días sin prórroga.

\section{D) PLANEAMIENTOS}

Planeamiento de la Provincia de Misiones

La Constitución de Misiones prevé la formulación de planeamientos para el desarrollo cultural y económico de la Provincia.

El objeto fundamental de la Junta Provincial de Planeamiento que se proyecta es el de orientar la inversión pública que favorezca la infraestructura necesaria para el desarrollo de la inversión privada. 


\section{E) BIENES Y SERVICIOS}

I) TRANSFERENCIA DE BIENES Y SERVICIOS NACIONALES A LA JURISDICCIÓN PROVINCIAL

Se estableció un sistema para promover la transferencia a las Provincias de aquellos servicios prestados por el Estado en sus demarcaciones.

Para el actual federalismo argentino, esta (provincialización» tiene especial interés. Se trata de devolver a las demarcaciones provinciales algunos de los servicios que pasaron al Estado por la mayor capacidad de iniciativa y recursos del mismo y cuya adscripción no sea necesario seguir manteniendo centralizada.

En los acuerdos que se lleva! a cabo con las entidades provinciales competentes deberá preverse el régimen de transferencia de bienes, el personal, los contratos en ejecución, el activo y pasivo de cada servicio debidamente individualizado con los recursos propios de tales servicios, y los fondos asignados en el presupuesto vigente para atender los gastos que originan los servicios que se transfieren.

\section{2) RÉGIMEN DE IMPUESTOS COMPARTIDOS}

La Ley 14.788 representa un régimen de compromiso, de participación, que restringiendo los poderes financieros retenidos por las Provincias, establece la distribución entre éstas y la Nación de la recaudación de los impuestos a los réditos, ventas, beneficios extraordinarios y ganancias eventuales. Durante el pasado año I96i ha representado un porcentaje del 68 por 100 del total de la recaudación para la Nación y el resto para las Provincias. El 32 por 100 que corresponde a éstas se distribuye por cuartas partes, de las cuales la primera es igual para todas las Provincias y las otras tres se distribuyen en proporción a la población, gastos y recursos, computados por la Comisión de Contralor e Indices, contra cuyas resoluciones pueden las Provincias recurrir.

Se han elaborado anteproyectos de reformas de esta Ley y de la Ley I4.390 que establece el régimen de participación de los impuestos internos.

Si tales reformas avivaron la esperanza de las Provincias a reivindicar su declinada voluntad autonómica, el bien común aconseja que en las circunstancias porque atraviesa la Naciōn argentina se mantenga el sistema de participación, establecido «siempre que la defensa, seguridad común y bien general del Estado lo exijan». 